\title{
Fronteiras terapêuticas em expansão: engenharia de tecidos e células-tronco
}

\author{
Roberto Rocha*
}

Na última década, a pesquisa em Odontologia tem avançado de forma expressiva no campo da engenharia de tecidos. A busca por formas de permitir a reparação tecidual, e até mesmo a formação de tecidos novos, tem como objetivo ampliar de forma drástica as possibilidades terapêuticas nas diferentes áreas. A engenharia de tecidos é uma possibilidade bastante promissora para fornecer tecido para reparos craniofaciais ${ }^{5}$. Somando-se a incidência das fissuras pré-forame incisivo, que envolvem o rebordo alveolar, com as fissuras do tipo transforame incisivo, a presença da fenda alveolar, parcial ou completa, atinge cerca de 70\% dos pacientes portadores de fissura labiopalatal.

Sob a óptica do tratamento ortodôntico, a presença da fenda alveolar é o ponto de maior complexidade terapêutica, pois impõe limites à movimentação dentária na área adjacente à fenda. É crítica a atenção para a limitação que essa circunstância impõe à reabilitação do pacien$t^{1,2,11,12}$. Com intuito de fazer frente a essa dificuldade, a utilização do enxerto ósseo alveolar secundário tem sido o protocolo de eleição. Não obstante sua eficácia esteja fartamente registrada na literatura e na prática clínica, é um procedimento que envolve aspectos de complexidade como o custo, envolvendo anestesia geral, necessidade de ortopedista quando o sítio doador é a crista ilíaca, e sua morbidade, entre outros. Novas descobertas estão sinalizando na direção do desenvolvimento de estratégias menos invasivas e tão eficazes quanto. A Associação Americana de

Como citar este artigo: Rocha R. Fronteiras terapêuticas em expansão: engenharia de tecidos e células-tronco. Dental Press J Orthod. 2011 Sept-Oct; 16(5):17-9.
Cirurgiões Ortopedistas sugere que, em face da elevada demanda de enxertias, seja estimulado o desenvolvimento e oferta de "substitutos aos enxertos ósseos convencionais". Em recente estudo ${ }^{5}$, células-tronco embrionárias foram diferenciadas em cartilagem e, então, implantadas em defeitos ósseos cranianos produzidos artificialmente. $\mathrm{Na}$ comparação com o grupo controle, o grupo que recebeu o tecido implantado teve uma resposta de reparo significativamente mais rápida.

A biologia das células-tronco tem se tornado uma importante área de conhecimento para entender o processo da regeneração tecidual. Para a bioengenharia é essencial uma tríade composta por células-tronco, ou progenitoras, uma matriz que funcione como arcabouço e proteínas sinalizadoras, denominadas fatores de crescimento, como estímulo para diferenciação celular ${ }^{10}$. Em geral, as células-tronco apresentam duas grandes características: têm a capacidade de autorrenovação e, quando se multiplicam, podem permanecer com as características de células-tronco ou se diferenciar em uma gama de outros tipos celula$\mathrm{res}^{6,7}$. A polpa dentária figura entre os tecidos mais ricos em células-tronco mesenquimais, as quais têm enorme potencial de aplicação na engenharia de tecidos. Isso devido ao fato de que esse tipo de célula-tronco proveniente da polpa dentária é multipotente e tem elevada taxa de proliferação, dando a esse sítio doador destacado valor como importante fonte de células-tronco mesenquimais para utilização em reparação tecidual ${ }^{3}$.

»O autor declara não ter interesses associativos, comerciais, de propriedade ou financeiros que representem conflito de interesse, nos produtos e companhias descritos nesse artigo.

\footnotetext{
* Mestre e Doutor em Ortodontia pela UFRJ. Professor Adjunto de Ortodontia na UFSC. Diplomado pelo Board Brasileiro de Ortodontia e Ortopedia Facial.
} 
Em outro estudo, ficou comprovada a viabilidade da polpa dentária de dentes decíduos esfoliados como fonte viável de células-tronco para utilização na engenharia de tecidos pulpares $^{4}$. A partir de células-tronco mesenquimais retiradas da polpa de dentes permanentes, já foi possível desenvolver tecido pulpar, com características muito próximas da normalidade, sobre um arcabouço previamente prepara$\mathrm{do}^{8}$. Há uma tendência atual maior na direção do uso das células-tronco adultas do que as células-tronco embrionárias. Algumas das razões que justificam essa escolha são: as adultas envolvem questões éticas menos complicadas e oferecem maior facilidade de controle no aspecto de diferenciação e da proliferação celular. As de origem embrionária tendem a apresentar um crescimento mais desordenado e descontrolado, podendo até atingir um aspecto tumoral. Esse fato pode estar relacionado ao contexto sinérgico e de memória funcional dessas células. As de origem embrionária estão sintonizadas em uma fase do desenvolvimento em que as taxas de diferenciação e crescimento são muito altas, quando comparadas com as das células-tronco adultas.

No estágio atual, a formação de tecidos isoladamente parece ser uma promessa mais palpável em um cenário não tão longínquo ${ }^{7}$. Atualmente, dentes que sofrem perda de estrutura radicular associada à movimentação ortodôntica, por exemplo, têm um prognóstico de impossibilidade na recuperação do tecido perdido. Isso tende a alterar positivamente a evolução das pesquisas. A papila apical difere da polpa por apresentar menos componentes celulares e vasculares ${ }^{9}$. No entanto, ficou evidenciado que as células-tronco da papila apical demonstram potencial elevado de diferenciação e reparação. A constatação disso pode ser vista em algumas situações em dentes permanentes, com rizogênese incompleta e traumatizados, que sofreram a extirpação da polpa e subsequente obturação do canal e, mesmo assim, seguiram no processo da rizogênese. Esses achados abrem a possibilidade de usar células-tronco da papila apical (CTPA) e outros tipos de células-tronco para reparação da polpa e dentina conjugadas com a associação de CTPA e células-tronco do ligamento periodontal. Essa possibilidade tem sido chamada de ENGENHARIA DA BIORAIZ ${ }^{6}$.

O desenvolvimento tecidual envolve a sinergia de eventos e substâncias em um espectro bastante amplo e complexo. O entendimento conclusivo dos agentes, suas funções e do contexto sinérgico indica que há um longo caminho a ser percorrido. No entanto, são muito promissores os resultados e, com o aprimoramento dos métodos de pesquisa, a evolução se acerca. Uma grande dificuldade que ainda permanece é conseguir o desenvolvimento do conjunto das fibras do ligamento periodontal adequadamente estruturadas e com as interfaces de cemento e osso alveolar. O conhecimento já permite um bom entendimento de como programar e estimular a diferenciação; porém, controlar a localização e a quantidade de crescimento ainda permanece como um árduo desafio a ser vencido.

De 15 anos atrás, quando iniciaram as pesquisas com células-tronco, para a atualidade, o conhecimento nessa área tem se ampliando de forma exponencial. No entanto, para cada nova descoberta descortinam-se questionamentos éticos, indagações e novos desafios. Há a necessidade premente de que os cursos de graduação em Odontologia revisem os conteúdos para o aprendizado da biologia celular, à luz dos conhecimentos atuais, e os ampliem também para a biologia molecular. O ortodontista contemporâneo deve rever e aprofundar seus conhecimentos nessas áreas. Isso desponta como condição precípua para que se possa incorporar as novas tecnologias advindas da bioengenharia e estender aos pacientes os benefícios significativos que se avizinham. 


\section{REFERÊNCIAS}

1. Abyholm F, Bergland O, Semb G. Secondary bone grafting of alveolar clefts. Scand J Plast Reconstr Surg. 1981;15:127-40.

2. Boyne PJ, Sands NR. Combined orthodontic-surgical management of residual palato-alveolar cleft defects. Am J Orthod. 1976;70(1):20-37.

3. Casagrande L, Cordeiro MM, Nör SA, Nör JE. Dental pulp stem cells in regenerative dentistry. Odontology. 2011;99(1):1-7. Epub 2011 Jan 27.

4. Cordeiro MM, Dong Z, Kaneko T, Zhang Z, Miyazawa M, Shi S, et al. Dental pulp tissue engineering with stem cells from exfoliated deciduous teeth. J Endod. 2008;34(8):962-9.

5. Doan L, Connor K, Heather L, English J, Gomez H, Johnson E, et al. Engineered cartilage heals skull defects. Am J Orthod Dentofacial Orthop. 2010;137(2):162.e1-9.

6. Huang GT, Sonoyama W, Liu Y, Liu H, Wang S, Shi S. The hidden treasure in apical papilla: the potential role in pulp/dentin regeneration and bioroot engineering. J Endod. 2008;34(6):645-51

7. Huang GT. A paradigm shift in endodontic management of immature teeth: conservation of stem cells for regeneration. J Dent. 2008;36(6):379-86.
8. Sakai VT, Cordeiro MM, Dong Z, Zhang Z, Zeitlin BD, Nör JE. Tooth slice/scaffold model of dental pulp tissue engineering. Adv Dent Res. 2011;23(3):325-32.

9. Sonoyama W, Liu Y, Yamaza T, Tuan RS, Wang S, Shi S, et al. Characterization of the apical papilla and its residing stem cells from human immature permanent teeth: a pilot study. J Endod. 2008;34(2):166-71.

10. Soares AP, Knop LAH, Jesus AA, Araújo TM. Células-tronco em odontologia. Rev Dental Press Ortod Ortop Facial. 2007:12(1):33-40.

11. Stellmach RK. Bone grafting of the alveolus followed by orthopaedic alignment of the alveolar arch in infants with complete CLP. Oral Surg. 1963;16(8):897-912.

12. Turvey TA, Vig K, Moriaty J, Hoke J. Delayed bone grafting in the cleft maxilla and palate. A retrospective multidisciplinary analysis. Am J Orthod. 1984;86(3):244-56.
Endereço para correspondência

Roberto Rocha

Duarte Schutel $306-6^{\circ}$ andar, Centro

CEP: 88.015-640 - Florianópolis / SC

E-mail: rochafln@gmail.com 